\title{
Developing Concept of Healthy Island: A Systematic Review
}

\author{
Nurul Syahriani ${ }^{1,2 *}$ (D) Sukri Palutturi ${ }^{2}$ \\ ${ }^{1}$ Department of Public Health, Faculty of Sciences and Technology, Avicenna Institute of Technology and Health, Kendari, \\ Indonesia; ' 2 Department of Health Administration and Policy, Faculty of Public Health, Hasanuddin University, Makassar, \\ Indonesia
}

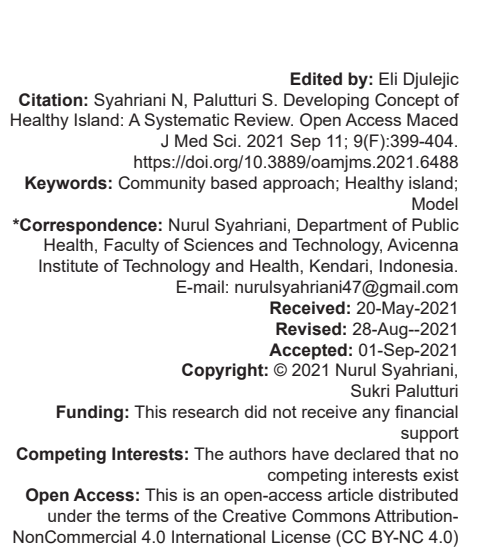

\section{Introduction}

Healthy Island is a vision that has been widely developed by the Ministry of Health in the Pacific region for health development. This is due to the many dangerous health problems in the archipelagic countries. The problem in the archipelago is climate change. Climate change is a problem in the archipelago because it has impacts that can pose health risks, such as diseases transmitted through vectors, food, and water [1]. Apart from climate change, the lack of a holistic management plan by local governments that integrates environmental issues is also a problem in the archipelago [2].

In addition, other problems in the archipelago that can affect the health of the community are economic problems, population growth, health facilities, and access to health services [3]. Mental health and disability are also significant burdens [4]. Based on the problems that exist in the archipelago and the impact it causes, a meeting of ministers in the Pacific Islands is held for the protection and promotion of health in the archipelago by establishing the Healthy Archipelago Movement as the main force for public health [5].
The Healthy Island concept was envisioned at the first Pacific Health Ministers Meeting on Yanuca Island, Fiji, in 1995 in response to the emerging health challenges faced by Pacific island nations. The Yanuca Declaration [6] emphasized that Healthy Island should be a place where: Children are nurtured in body and mind; environments invite learning and leisure; people work and age with dignity; Ecological balance is a source of pride, and the ocean which sustains us is protected [7].

Healthy Island seeks to improve the health of the people living and working in the archipelago [8]. This approach is in line with the Ottawa Charter [9] which seeks to recognize the importance of social and physical environmental influences on health leading to health promotion in environments such as schools, workplaces, churches, villages, and cities [10], [11].

The Healthy Island Initiative in several Pacific Island countries and the Maldives focuses on various aspects. Some countries have focused on controlling certain diseases or health problems, such as controlling malaria in the Solomon Islands. Others focus on environmental health and health promotion initiatives (Fiji Islands) or water supply and sanitation through community development (Tonga). Others are still implementing community-based health promotion 
projects (Cook Islands, Kiribati, Niue, Tuvalu, and Samoa) [12]. However, the process of implementing healthy island has not been widely implemented at the national level. This is due to the lack of coordination in the implementation of healthy islands, the lack of the concept of healthy islands, and the need for promotion or introduction in the implementation of healthy islands [13]. Therefore, this article aims to identify the formation of a healthy island concept.

\section{Methods}

\section{Data source}

To identify articles that are relevant to the study question, a literature search was carried out using three computerized bibiliographic databases, namely: Google Scholar, PubMed, and ScienceDirect, using the keywords healthy island, health problem in island, and using the Boolean operators "AND" and "OR". Articles are selected based on the issues of the last 10 years, namely, 2010-2020. Based on a search using keywords there were found 12.669 articles. All selected references are imported into Endnote.

\section{Study selection}

This review article is arranged thematically using PRISMA 2015. This is due to PRISMA is an appropriate method for screening articles to compile a systematic review consisting of various studies which have methods, concepts, as well as relevant results.

\section{Extraction data}

This review article was compiled by firstly screening the articles by looking at the inclusion criteria and exclusion criteria which can be seen in Table 1. The author screens all publications by looking at the year of publication, after that, filters based on the issue and language used in the article, articles that are not appropriate then issued. Articles chosen will be selected more stringently by reading the article as a whole to look at the methods, concepts used in solving the problem in archipelago, results, conclusions, and recommendations by the author. Articles not in line with the inclusion and exclusion criteria will be deleted and the chosen article will be processed according to the aforementioned criterions.

Table 1: Criteria in Literature search

\begin{tabular}{ll}
\hline Criteria & Description \\
\hline Exclusion & Editorial, Systematic Review/Literature Review, Conference Process, \\
& Protocol Study, Meta-Analysis \\
& Double Publication \\
& Articles not in English and not Full Text \\
Inclusion & $\begin{array}{l}\text { Articles not limited by concepts and research location } \\
\text { Focus on archipelagic problem solving and development of healthy island } \\
\\
\text { Published in the past 10 years (2010-2020) }\end{array}$ \\
\hline
\end{tabular}

According to Figure 1, out of the 12,669 articles retrieved from three databases and then were screened. After the screening process, and from the screening result, the data were extracted to see the number of articles that meet the criterion, in which would be analyzed further. According to the screening and the Proper test, there were found 12 articles which meets the criteria of being published from 2010 to 2020.

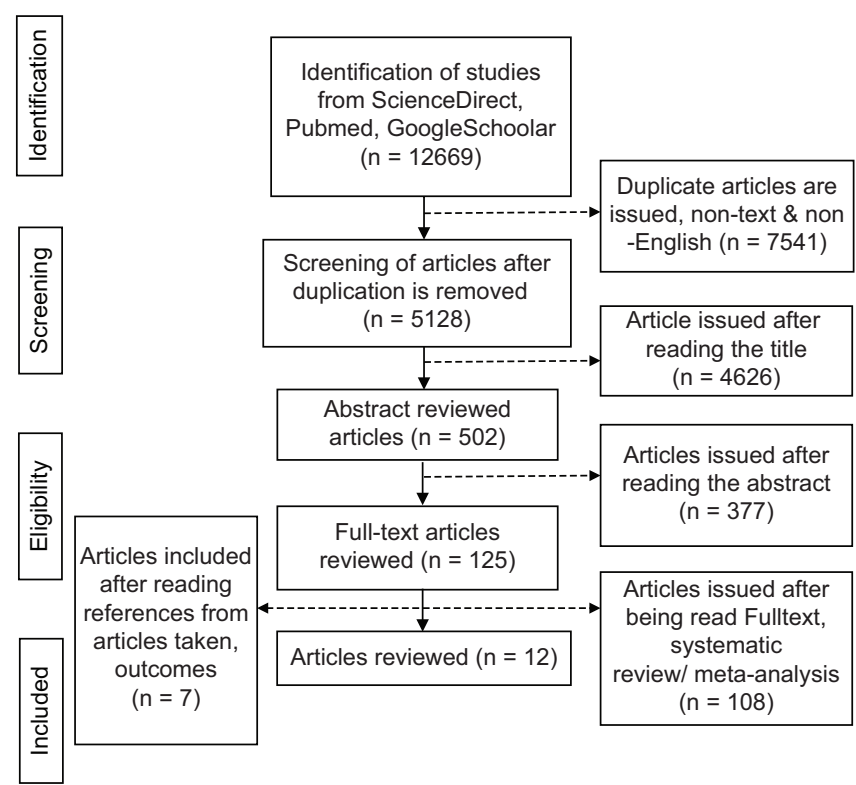

Figure 1. PRISMA Flow Diagram

\section{Data analysis}

At this stage, the collected data are gathered for a data analysis. During this stage, the chosen articles are grouped based on (1) research design (2) programs or concept used.

\section{Results and Discussion}

\section{Research design}

After filtering using the PRISMA model, 12 articles were retrieved. These articles show several designs which are used in a myriad of other researches in other countries including Indonesia which are used to address the problem in the archipelago and considered to be an obstacle in realizing healthy island. These designs can be viewed on Table 2 , majority of articles uses a qualitative and quantitative design [14], [15]; using qualitative designs [16], [17]; using quantitative design with descriptve survey [18]; using descriptive statistic design [19]; cohort design [20]; retrospective analysis [21]; culture-based method, quantitative polymerase chain reaction ( $\mathrm{PPCR}$ ) and $16 \mathrm{~S}$ ampliconbased sequencing [22]; descriptive thematic analysis [23]; descriptive study [24]. 
Table 2: Research design

\begin{tabular}{|c|c|c|c|c|}
\hline S. No & Location & Object & Design & Reference \\
\hline 1 & $\begin{array}{l}\text { Barang Caddi } \\
\text { Island in } \\
\text { Makassar }\end{array}$ & Archipelago society & $\begin{array}{l}\text { Quantitative with } \\
\text { descriptive survey } \\
\text { approach }\end{array}$ & [18] \\
\hline 2 & Pacific Islands & $\begin{array}{l}\text { Pacific Island } \\
\text { Government and } \\
\text { regional and global } \\
\text { data }\end{array}$ & $\begin{array}{l}\text { Qualitative and } \\
\text { quantitative }\end{array}$ & [15] \\
\hline 3 & $\begin{array}{l}\text { Islands in } \\
\text { the Pacific } \\
\text { Micronesia } \\
\text { region }\end{array}$ & $\begin{array}{l}\text { Archipelagic } \\
\text { Government in the } \\
\text { Pacific Micronesia } \\
\text { region }\end{array}$ & $\begin{array}{l}\text { Qualitative and } \\
\text { quantitative }\end{array}$ & [14] \\
\hline 4 & Solomon Islands & Health facility & Cross-Sectional Study & [19] \\
\hline 5 & $\begin{array}{l}\text { Massachusetts } \\
\text { and Rhode } \\
\text { Islands }\end{array}$ & $\begin{array}{l}\text { Baby live birth with } \\
\text { and without defects }\end{array}$ & Cohort study & [20] \\
\hline 6 & Samoa & Samoan people & Qualitative research & [16] \\
\hline 7 & Pacific Islands & $\begin{array}{l}\text { Representatives of } \\
\text { community leaders, } \\
\text { teachers, and } \\
\text { parents. }\end{array}$ & Qualitative research & [17] \\
\hline 8 & Pacific Islands & Remote islanders & $\begin{array}{l}\text { Store and Forward } \\
\text { Program }\end{array}$ & [25] \\
\hline 9 & $\begin{array}{l}\text { Island in } \\
\text { Thailand }\end{array}$ & Registered TB cases & Retrospective analysis & [21] \\
\hline 10 & $\begin{array}{l}\text { Tutuila Island } \\
\text { and nearby } \\
\text { island Aunuu }\end{array}$ & Rainwater & $\begin{array}{l}\text { Culture-based methods, } \\
\text { quantitative polymerase } \\
\text { chain reaction, and } \\
\text { 16S-based amplicon } \\
\text { sequencing }\end{array}$ & [22] \\
\hline 11 & Fiji Islands & $\begin{array}{l}\text { A member of the } \\
\text { community from the } \\
\text { village of Taukei on } \\
\text { the island of Fiji }\end{array}$ & $\begin{array}{l}\text { Descriptive thematic } \\
\text { analysis }\end{array}$ & [23] \\
\hline 12 & Pacific Islands & TB patient & Descriptive study & [24] \\
\hline
\end{tabular}

Literature search does not limit the design only on a singular design. On this particular research it qualitative data were retrieved using a semi-structured interview with Ministers and Government Official in the corresponding Archipelago of the Pacific Isle, healthcare employees, and community members and also using a document review. A quantitative approach consists of reviewing secondary data found from regional and global data gathering. Other research using the same design, in which the research uses the same process to grade the vulnerability of each nation and planning a strategy to manage any and all health-related problems caused by climate changes in accordance with WHO guidelines and also inserting qualitative and quantitative elements. These elements also includes stakeholders, community survey, experts consensus, and available climate data analysis [14]. In another study using a qualitative design which was carried out with the object of research the Samoan community with a total sample of 73 people aged over 18 years and then divided into six groups. Then interviews were conducted using a semi-structured interview guide which was based on the conceptual model of the European Health Literacy project (HLS-EU). The data were then decoded, transcribed, coded, and categorized as part of the qualitative analysis [16]. Another qualitative design uses informants who come from representatives of community leaders, teachers, and parents. This study identifies factors that promote or hinder healthy living, (identify community resources that can be utilized to promote healthy living and prioritize potential environmental intervention strategies [17].

The other research design uses a quantitative design with a descriptive survey approach in which the research design analyzes a healthy diet as an indicator of a healthy island. This study used 153 respondents through purposive sampling technique. Data analysts used chi-square tests and logistic regression tests to identify indicators associated with healthy island indicators [18]. In addition, to solve health problems in the islands of other research using cross-sectional study design and cohort studies. Whereas in a study that used a cross-sectional study design, the study design assessed the quality of care for newborns in the archipelago, the study was conducted in five provincial hospitals using an assessment tool from the World Health Organization [19].

Other studies using a cohort study design. A cohort study is an observational study that studies the relationship between exposure and disease by selecting two or more study groups based on exposure status and then being followed up (followed up) for a certain period so that disease incidence can be identified and calculated. This study looked at the effect of exposure to drinking water containing PCE on first-trimester mothers in the islands. This study was divided into two groups, the case group, and the control group. The case group consisted of live and dead babies born between 1968 and 1995 in 28 different cities. The sample in the case group consisted of infants with 268 cases of central nervous system defects, 112 cases of cleft mouth or cleft lip, and 94 cases of hypospadias. Meanwhile, the control cases were selected randomly, using live and non-disabled babies born in the same period of time and geographic area with a total of 771 cases. Important notes and self-processed questionnaires were used to collect information consisting of identity, diagnosis of birth defects, and other relevant data. PCE exposure during the first trimester was estimated using a water distribution system modeling software combining leaching and transport models [20].

Retrospective analysis, culture-based methods, qPCR, and 16S-based amplicon sequencing, descriptive thematic analysis, and descriptive studies are other designs used in various studies to solve problems in the islands. A retrospective analysis in this study, using data on tuberculosis cases registered in two districts in the archipelago with different transportation accessibility, then made a comparison of the level and success of management [21]. Other designs using culture-based methods, qPCR, and 16S-based amplicon sequencing are methods used to assess water quality from common drinking water sources including rainwater stored in tanks, untreated river water, municipal well water. untreated, and treated municipal tap water samples [22].

Another research design using thematic descriptive analysis. This research is a Community Based Participatory Research (CBPR) project, involving community members from the rural iTaukei village in the Fiji Islands. This study was conducted to understand the social and cultural components, 
which contribute to obesity in the Indigenous rural areas of Fiji. Data collection was carried out through community consultation and semistructured interviews [23]. Another study design used descriptively. This study design was used to calculate the proportion of TB patients who completed TB treatment and add up the national incidence, prevalence, and mortality estimates, provided by the $\mathrm{WHO}$, to produce regional incidence, prevalence, and mortality rates per 100,000 population [24]. Other designs is a Pacific Island Health Care Project (PIHCP) providing humanitarian medical assistance, referral/consultation/care to $>500,000$ indigenous people of remote islands using a simple store-andforward program design to connect USAPI with Tripler Army Medical Center. This application can attach images for consultation via email [25].

\section{Program or concept}

Various types of programs or concepts are used to solve health problems in the islands, which later this program or concept will be used as the basis for the realization of a healthy island. Healthy diet [18], Health development review [15], Concept of a climate change, and adaptation health vulnerability assessment and planning project by the World Health Organization and health sector partners [14], the World health organization assessment [19], Modeling exposure to tetrachlorethylene [20], Conceptual model of European Health Literacy Projection (HLS-EU) [16], Community involvement of children's healthy living program (CEP) (CEP) [17], PIHCP [25], Data analysis of registered TB cases newly registered [21], RHRW [22], CBPR Approaches [23] and Descriptive Epidemiology [24] are programs or concepts used in the literature review (Table 3).

Table 3: Pogram or concept

\begin{tabular}{|c|c|c|c|}
\hline $\begin{array}{l}\text { S. } \\
\text { No }\end{array}$ & Program/Concept & Benefit & References \\
\hline 1 & Healthy Diet & Preventing overweight and obesity. & [18] \\
\hline 2 & Health Development Review & Increasing Health Indicators & [15] \\
\hline 3 & $\begin{array}{l}\text { Project Grading Concept and } \\
\text { Health Vulnerability Planning } \\
\text { due to Climate Change and } \\
\text { Adaptation by the WHO and } \\
\text { Healthcare Sector Partners }\end{array}$ & Climate Change Adaptation & [14] \\
\hline 4 & WHO Grading & Neonatal Care Quality & [19] \\
\hline 5 & $\begin{array}{l}\text { Modelling Tetrachloroethylene } \\
\text { exposure }\end{array}$ & $\begin{array}{l}\text { Identifying contaminated drinking } \\
\text { water and occurences of birth } \\
\text { defects }\end{array}$ & [20] \\
\hline 6 & $\begin{array}{l}\text { Europe Health Literation } \\
\text { Conceptual Model(HLS-EU) }\end{array}$ & $\begin{array}{l}\text { Preventing Non-Communicable } \\
\text { Diseases }\end{array}$ & [16] \\
\hline 7 & $\begin{array}{l}\text { Public Involvement in Healthy } \\
\text { Child Program (CHL) (CEP) }\end{array}$ & Preventing childhood obesity & [17] \\
\hline 8 & $\begin{array}{l}\text { Pacific island health care } \\
\text { project }\end{array}$ & $\begin{array}{l}\text { Providing referral/consultation/ } \\
\text { humanitarian medical care }\end{array}$ & [25] \\
\hline 9 & New TBC Case Data Analysis & $\begin{array}{l}\text { Comparison and Sucess Level of } \\
\text { Management }\end{array}$ & [21] \\
\hline 10 & RHRW & $\begin{array}{l}\text { Evaluate and Compare water quality } \\
\text { from drinkable water source }\end{array}$ & [22] \\
\hline 11 & $\begin{array}{l}\text { Community-Based } \\
\text { Participatory Research } \\
\text { Approach (Community Based } \\
\text { Participatory Research) }\end{array}$ & Obesity prevention & [23] \\
\hline 12 & Descriptive Epidemiology & $\begin{array}{l}\text { Summarizing TBC Epidemic in The } \\
\text { Pacific }\end{array}$ & [24] \\
\hline
\end{tabular}

Obesity, climate change, non-communicable diseases, infectious diseases, water quality, referral services are various problems that exist in the archipelago in the literature review. To overcome this, various programs or concepts were created. A healthy diet is a program used to prevent weight or obesity. Where the program looks at the diet and food consumption of the island community so that obesity does not occur [18]. Obesity does not only occur in adults but also occurs in children, other studies examine obesity in children using the Community Involvement Program of the CHL CEP. Programs are devoted to children's environments to more actively promote healthy food intake to prevent childhood obesity. This program seeks to develop, implement and evaluate community-based environmental interventions to address six behavioral targets that affect health proposed by researchers including increasing consumption of fruits and vegetables, increasing water intake, reducing intake of sugary drinks, increasing physical activity, increasing sleep duration, and reducing sleep time. in front of a screen (e.g. TV screen use and recreation) [17]. The CBPR approach is another program created for obesity prevention. The CBPR program is a collaborative approach program that involves all partners or stakeholders. CBPR begins by looking at the problems that occur in the community, this is done to determine solutions by combining knowledge and action to achieve social change [23].

Modeling exposure to tetrachlorethylene and RHRW is another program or concept used to address other problems in the islands, namely, water quality problems. Research with the concept of modeling exposure to tetrachlorethylene which in the concept identifies contaminated drinking water that causes birth defects. In this concept, modeling is carried out using an integrated pipe scheme approach, water use, and PCE distribution to determine the rate and direction of water flow and the amount of PCE in the entire consumption point distribution system [20]. Another research with the concept of RHRW, where this study evaluates and compares the quality of rainwater compared to drinking water sources in general. The RHRW concept uses rainwater by collecting it into a tank and then testing its quality using culturebased methods, qPCR, and 16S amplicon sequencingbased. This is done because rainwater is an alternative water source that many islanders can use for drinking and other household purposes when groundwater and/or surface water sources are contaminated, limited, or not available at all [22].

The conceptual model of the European Health Literacy Project (HLS-EU) was created to prevent noncommunicable diseases, descriptive epidemiology to summarize the epidemiology of TB in the Pacific as well as an analysis of data on newly registered TB cases for comparative rates and successful management. The European Health Literacy Project (HLS-EU) conceptual model is a conceptual model that focuses on how people 
access, understand, assess, and apply information for decision-making in their lives regarding health, disease prevention, and health promotion. This concept also shows how health literacy is influenced by the individual himself, situational and social determinants [16]. While the concept of descriptive epidemiology was created to summarize the epidemiology of TB in the Pacific. This concept was created to assess the incidence of cases reported annually by the Pacific Island National TB Program to the WHO. This concept also describes the estimates of incidence, prevalence, and mortality provided by WHO [24]. Another research concept is to analyze the registered TB case data for comparison level and management success. This concept focuses on specific data on newly registered tuberculosis and the efficacy of antituberculosis drugs. These data were collected and recalculated and the level of comparison was carried out using the Z-test proportion [21].

Health development review to improve health indicators, this program conducts a health development review over a period and discusses implications for the achievement of health-related Sustainable Development Goals [15]. Concept of a climate change and adaptation health vulnerability assessment and planning project by the World Health Organization and health sector partners. This concept has adapted to climate change and minimized the impact of climate change by conducting health tests and traditional health governance structures. However, the success of this program depends on the strong relationship and partnership between the actors involved in the program [14]. World Health Organization Assessment is a program or concept created to see the quality of neonatal care. The assessment team consisted of a pediatrician from a national referral hospital and two patients from a national referral hospital accompanied by a visiting pediatrician. The assessment tool is adapted from the World Health Organization (WHO) assessment tool used to assess the quality of hospital care. The assessment covers all areas of the facility where the newborn cares (maternity wards, postnatal wards, neonates, wards and emergency rooms, and outpatients). Data were collected through observation of facilities and equipment as well as review of incoming treatment room records during the previous 12 months [19]. PIHCP is a program to provide referrals/ consultation/humanitarian medical care. This program provides electronic mail accompanied by pictures for consultation and referral of patients residing in the islands. This program was further developed with a simple telemedical consultation/referral method and demonstrated the use of an Internet-based consultation/ referral platform. PIHCP has also added a statement/ consent form to the consultation page of each patient, as well as adapting the language used by residents on the islands [25]. This study has limitations in the amount of literature related to specific Healthy Islands. In addition, the design and concept of a healthy island have not collaborated between institutions in realizing a healthy island, have not carried out participatory health interventions based on culturally sensitive communities that deal with the family as a whole, build health literacy to overcome major public health problems such as prevention of non-communicable diseases and eliminate barriers. In the health system, technology is needed that can keep up with the times and can be used in remote island areas to maximize access to health services, it is necessary to conduct further research to study and explore related to the development of the concept of a healthy island and the preparation of indicators of a healthy island that can be applied, especially in Indonesia.

\section{Conclusion}

Healthy island is a vision in an effort to fulfill the health needs of the island community. The implementation of the healthy island's vision and the fulfillment of its indicators are the spearheads in achieving the health status of the archipelagic community. Various studies with designs and programs have been carried out to overcome problems in the archipelago, especially health problems including improving health insurance, improving water quality, and eradicating infectious diseases. In overcoming health problems in the archipelagic region, it is not only necessary but a community-based approach is needed so that the archipelagic community can realize the need for health, which will facilitate various efforts in overcoming problems in the archipelagic region.

\section{References}

1. World Health Organization. Protecting the Health of Pacific Islanders from Climate Change and Environmental Hazards. Geneva: World Health Organization; 2020. https://doi. org/10.7748/ns.23.31.31.s36

2. Sridhar R, Sachithanandam V, Mageswaran T, Mahapatra M, Badarees $\mathrm{KO}$, Purvaja $\mathrm{R}$, et al. Small island management: A case study of the Smith Island, North Andaman, India. Environ Dev Sustain. 2019;22(8):8211-28. https://doi.org/10.1007/ s10668-019-00553-8

3. Binns C, Hokama T, Low WY. Island health: Hope and challenges for public health. Asia Pac J Public Health. 2010;22(1):19-24. https://doi.org/10.1177/1010539509357782 PMid:20032031

4. World Health Organization. Addressing Noncommunicable Diseases in the Pacific Islands. Geneva: World Health Organization; 2020.

5. World Health Organization. Healthy Island. Geneva: World Health Organization; 2021.

6. World Health Organization. Yanuca Island Declaration on Health in the Pacific in the $21^{\text {st }}$ Century. Meeting of the Ministers 
of Health for the Pacific Island Countries. Geneva: World Health Organization; 1995.

7. World Health Organization. Healthy Islands: Best Practices in Health Promotion in the Pacific. Geneva: World Health Organization; 2017.

8. Ritchie JE, Hine B. Healthy Islands: From concept to practice. Pac Health Dialog. 1998;5(1):180-6.

9. World Health Organization. Milestones in Health Promotion Statements from Global Conferences. Geneva: World Health Organization; 2009.

10. World Health Organization. Regional Framework for Health Promotion: 2002-2005. Manila: World Health Organization Regional Office for the Western Pacific; 2002.

11. Poland B, McCall D. Settings for health promotion: An analytical framework to guide intervention design and implementation. Health Promot Pract. 2009;10(4):50516. https://doi. org/10.1177/1524839909341025 PMid:19809004

12. World Health Organization. Types of Healthy Settings. Geneva: World Health Organization; 2020. Available from: https://www.who.int/healthy_settings/types/islands/en. [Last accessed on 2021 Mar 14].

13. Galea G, Powis B, Tamplin SA. Healthy Islands in the Western Pacific-international settings development. Health Promot Int. 2000;15(2):169-78. https://doi.org/10.1093/heapro/15.2.169

14. Mclver L, Bowen K, Hanna E, Iddings S. A "Healthy Islands" framework for climate change in the Pacific. Health Promot Int. 2017;32(3):549-57. https://doi.org/10.1093/heapro/dav094 PMid:26430174

15. Matheson D, Park K, Soakai TS. Pacific island health inequities forecast to grow unless profound changes are made to health systems in the region. Aust Health Rev. 2017;41(5):590-8. https://doi.org/10.1071/ah16065 PMid:28214473

16. Bollars C, Sorensen $\mathrm{K}$, de Vries N, Meertens R. Exploring health literacy in relation to noncommunicable diseases in Samoa: A qualitative study. BMC Public Health. 2019;19(1):1151. https:// doi.org/10.1186/s12889-019-7474-x

PMid:31438907

17. Fialkowski MK, DeBaryshe B, Bersamin A, Nigg C, Guerrero RL, Rojas $G$, et al. A community engagement process identifies environmental priorities to prevent early childhood obesity: The children's healthy living $(\mathrm{CHL})$ program for remote underserved populations in the US affiliated Pacific Islands, Hawaii and
Alaska. Matern Child Health J. 2014;18(10):2261-74. https://doi. org/10.1007/s10995-013-1353-3

PMid:24043557

18. Rosmanely S, Palutturi S, Saleh LM, Darmawansyah D, Arifin MA, Muhammad S. Healthy diet analysis as an indicator of healthy island on barrang caddi Island. Int J Psychosoc Rehabil. 2020;24(6):12321-6.

19. Tosif S, Nasi T, Gray A, Sadr-Azodi N, Ogaoga D, Duke T. Assessment of the quality of neonatal care in the Solomon Islands. J Paediatr Child Health. 2018;54(2):165-71. https://doi. org/10.1111/jpc. 13686 PMid:28905447

20. Aschengrau A, Gallagher LG, Winter M, Butler L, Fabian MP, Vieira VM. Modeled exposure to tetrachloroethylenecontaminated drinking water and the occurrence of birth defects: A case-control study from Massachusetts and Rhode Island. Environ Health. 2018;17(1):75. https://doi.org/10.1186/ s12940-018-0419-5

PMid:30400949

21. Yasri S, Wiwanitkit V. Newly registered tuberculosis: A comparison of rate and success of management in two island districts with different in accessibility of transportation in Thailand. Int J Mycobacteriol. 2019;8(4):371-73. https://doi. org/10.4103/ijmy.ijmy_140_19

PMid:31793508

22. Kirs M, Moravcik P, Gyawali P, Hamilton K, Kisand V, Gurr I, et al. Rainwater harvesting in American Samoa: Current practices and indicative health risks. Environ Sci Pollut Res Int. 2017;24(13):12384-92. https://doi.org/10.1007/ s11356-017-8858-z PMid:28357803

23. Singh KN, Gurung A. Understanding socio-cultural influences on food intake in relation to overweight and obesity in a rural indigenous community of Fiji Islands. Health Promot J Aust. 2020;1-7. https://doi.org/10.1002/hpja.397 PMid:32761937

24. Viney K, Hoy D, Roth A, Kelly P, Harley D, Sleigh A. The epidemiology of tuberculosis in the Pacific, 2000 to 2013. Western Pac Surveil Respon J. 2015;6(3):59-67. https://doi. org/10.5365/wpsar.2015.6.1.001 PMid:26668768

25. Person DA. The pacific island health care project. Front Public Health. 2014;2:175.

PMid:25353012 